\title{
Evolutionary Algorithms Applied to Antennas and Propagation: A Review of State of the Art
}

\author{
Sotirios K. Goudos, ${ }^{1}$ Christos Kalialakis, ${ }^{2}$ and Raj Mittra ${ }^{3,4}$ \\ ${ }^{1}$ Radiocommunications Laboratory, Aristotle University of Thessaloniki, 54124 Thessaloniki, Greece \\ ${ }^{2}$ Centre Tecnologic de Telecomunicacions de Catalunya-CTTC, Castelldefels, 08860 Barcelona, Spain \\ ${ }^{3}$ Department of Electrical and Computer Engineering, University of Central Florida, Orlando, FL 32816, USA \\ ${ }^{4}$ King Abdulaziz University, Jeddah 21589, Saudi Arabia \\ Correspondence should be addressed to Christos Kalialakis; christos.kalialakis@cttc.cat
}

Received 16 May 2016; Accepted 11 July 2016

Academic Editor: Jaume Anguera

Copyright ( 2016 Sotirios K. Goudos et al. This is an open access article distributed under the Creative Commons Attribution License, which permits unrestricted use, distribution, and reproduction in any medium, provided the original work is properly cited.

\begin{abstract}
A review of evolutionary algorithms (EAs) with applications to antenna and propagation problems is presented. EAs have emerged as viable candidates for global optimization problems and have been attracting the attention of the research community interested in solving real-world engineering problems, as evidenced by the fact that very large number of antenna design problems have been addressed in the literature in recent years by using EAs. In this paper, our primary focus is on Genetic Algorithms (GAs), Particle Swarm Optimization (PSO), and Differential Evolution (DE), though we also briefly review other recently introduced nature-inspired algorithms. An overview of case examples optimized by each family of algorithms is included in the paper.
\end{abstract}

\section{Introduction}

Several evolutionary algorithms (EAs) have emerged in the past decade that mimic the behavior and evolution of biological entities inspired mainly by Darwin's theory of evolution and its natural selection mechanism. The study of evolutionary algorithms began in the 1960s. Several researchers independently developed three mainstream evolutionary algorithms, namely, the Genetic Algorithms [1, 2], Evolutionary Programming [3], and evolution strategies [4] (Figure 1). EAs are widely used for the solution of single and multiobjective optimization problems and Figure 1 depicts some of the main algorithmic families.

Swarm Intelligence (SI) algorithms are also a special type of EA. The SI can be defined as the collective behavior of decentralized and self-organized swarms. SI algorithms include Particle Swarm Optimization (PSO) [5], Ant Colony Optimization [6], and Artificial Bee Colony (ABC) [7]. PSO mimics the swarm behavior of birds flocking and fish schooling [5]. The most common PSO algorithms include the classical Inertia Weight PSO (IWPSO) and the Constriction Factor PSO (CFPSO) [8]. The PSO algorithm is easy to implement and is computationally efficient; it is typically used only for real-valued problems. An option to expand PSO for discrete-valued problems also exists [9]. Other SI algorithms include (i) Artificial Bee Colony (ABC) [7], which models and simulates the behaviors of honey bees foraging for food, and (ii) Ant Colony Optimization (ACO) $[6,10,11]$, which is a population-based metaheuristic inspired by the behavior of real ants.

Differential Evolution (DE) $[12,13]$ is a population-based stochastic global optimization algorithm, which has been used in several real-world engineering problems utilizing several variants of the $\mathrm{DE}$ algorithm. An overview of both the PSO and DE algorithms and hybridizations of these algorithms along with other soft computing tools can be found in [14].

Other evolutionary techniques applied to antenna problems include the recently proposed Wind Driven Optimization (WDO) [15]; biogeography-based optimization (BBO); Invasive Weed Optimization (IWO) [16-20]; Evolutionary Programming (EP) [21, 22]; and the Covariance Matrix Adaptation Evolution Strategy (CMA-ES) [23, 24].

An important theorem which is pertinent to the performance of optimization algorithms is the so-called "No 


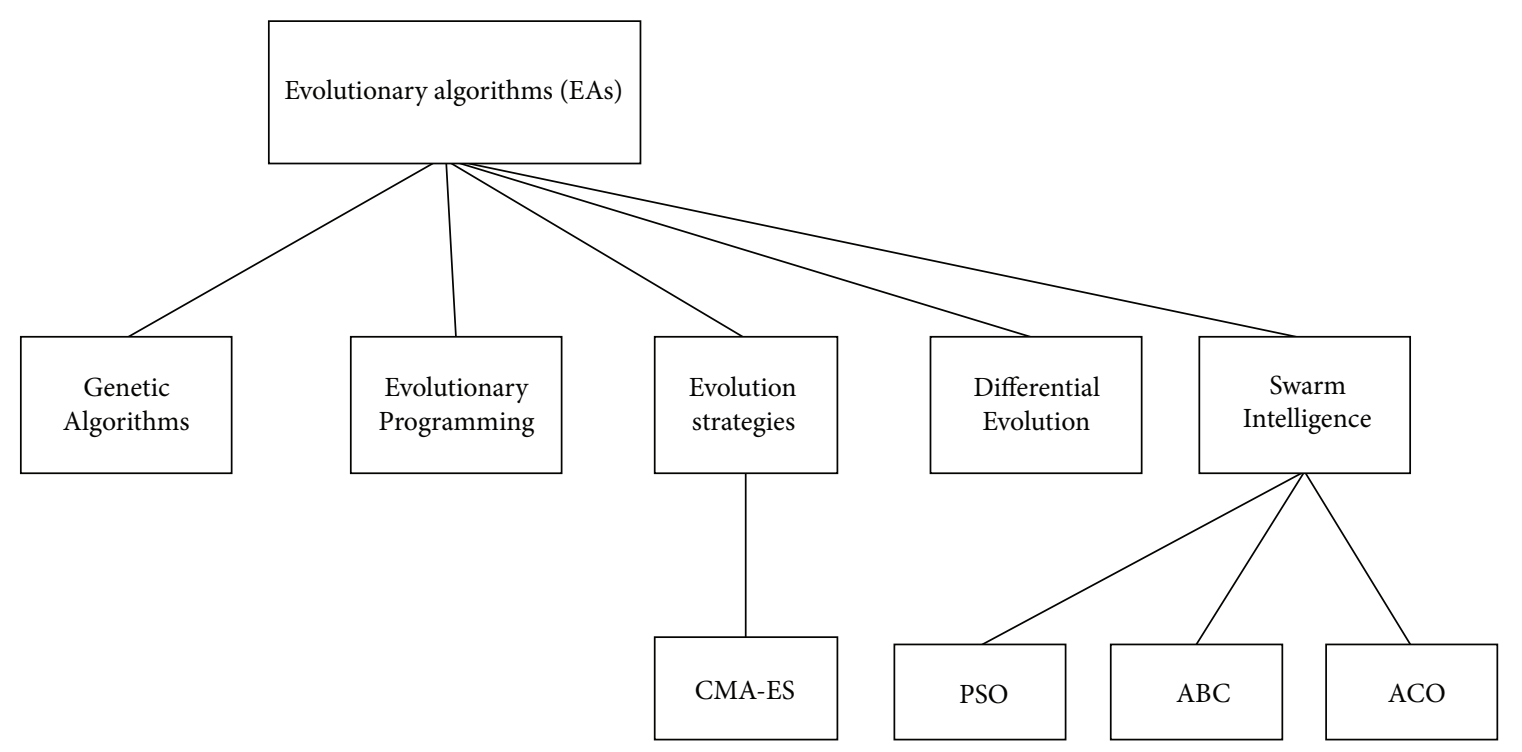

FIGURE 1: A diagram depicting main families of evolutionary algorithms.

Free Lunch" (NFL) theorem, which pertains to the average behavior of optimization algorithms over given spaces of optimization problems. It has been shown in [25] that when averaged over all possible optimization problems defined over some search space $X$, no algorithm has a performance advantage over any other. Additionally, in [26] the authors show that it is theoretically impossible to have a best generalpurpose universal optimization strategy, and the only way for one strategy to be superior to the others is when it focuses on a particular class of problems. It should be noted that a wide variety of optimization problems arise in the antenna domain and that it is not always an easy task to find the best optimization algorithm for solving each of them. Therefore, it is worthwhile to explore new optimization algorithms if we find that they can work well for the problem at hand. Optimization problems arising in the design and synthesis of antennas can benefit considerably from an application of the EAs, which can lead to unconventional solutions regarding position and excitation of the antenna elements in an array. Furthermore, the elements themselves can be geometrically designed by using the EAs.

The purpose of this paper is to briefly describe the algorithms and present their application to antenna design problems found in the recent literature.

Section 2 reviews the Genetic Algorithms (GAs). Section 3 focuses on PSO and Section 4 is devoted to DE. A brief overview of other EA algorithms is provided in Section 5. We describe the algorithms briefly and then present some statistics regarding the use of the algorithms in the literature. Additionally, for each algorithm some representative papers are referenced in the tables. Some open issues are discussed in Section 6, and conclusions are drawn in Section 7.

\section{Genetic Algorithms}

GAs, the most popular EAs, are inspired by Darwin's natural selection. GAs can be real or binary-coded. In a binary-coded
GA each chromosome encodes a binary string [27, 28]. The most commonly used operators are crossover, mutation, and selection. The selection operator chooses two parent chromosomes from the current population according to a selection strategy. Most popular selection strategies include roulette wheel and tournament selection. The crossover operator combines the two parent chromosomes in order to produce one new child chromosome. The mutation operator is applied with a predefined mutation probability to a new child chromosome.

A search in the Scopus database shows that there are 65762 conference papers and 94510 journal papers related to GAs from 1977 to 2016. Figure 2 shows the number of papers related to GAs and antennas over the last 15 years. Additionally, the search in the same database using the keywords GAs and Antennas reveals a total number of 2807 papers (both journal and conference). Tutorials and applications of GAs to electromagnetics can be found in $[29,30]$.

Table 1 lists selected papers that use GAs (mostly binarycoded) for antenna design. Several papers exist in the literature that apply GAs for array synthesis. A binary-coded GA has been applied for linear and planar array synthesis in $[31,32]$, among others, while a GA that uses decimal operator has been used in [33]. The problem of array thinning has been addressed in the literature using binary-coded GAs in [34], while the array-failure correction problem has been addressed by using the real-coded GAs in [35]. A simple GA has been used for the synthesis of time-modulated arrays in [36]. Different antenna types have been designed using the GAs, for example, wire antennas in [37-40], patch antennas in [41, 42], and RFID tags in [43]. Other GA-type algorithms, such as a mixed integer GA, have also been applied in [44] to several different antenna design problems. An improved GA for the design of linear aperiodic arrays and a binarycoded GA which uses two-point crossover (instead of the usual one point) have been used in [45] for the design of 
TABLE 1: Selected journal papers that use GAs for antenna design.

\begin{tabular}{lll}
\hline Problem & Algorithm(s) used \\
\hline Thinned arrays & Binary-coded GA & Ref. \\
Wire antennas and Yagi-Uda antenna & Binary-coded GA & Decimal operators GA \\
Array synthesis & Real-coded GA & [34]-40] \\
Array-failure correction & Binary-coded GA and hybrid GA with simulated annealing \\
Linear and planar array synthesis & (SA) \\
Broadband patch antennas and dual-band patch & Binary-coded GA and parallel GA \\
antennas & Binary-coded GA \\
RFID tags & Simple GA \\
Time-modulated linear arrays & Mixed integer GA 32] \\
Linear array design, thinned subarrays, and circularly & \\
polarized patch antenna & Improved GA \\
Linear aperiodic arrays design & Binary-coded GA and two-point crossover \\
Low RCS slot patch antennas & chaos genetic algorithm \\
T-shaped MIMO radar antenna array & Binary-coded GA \\
Quad-band patch antenna & [41, 42] \\
\hline
\end{tabular}

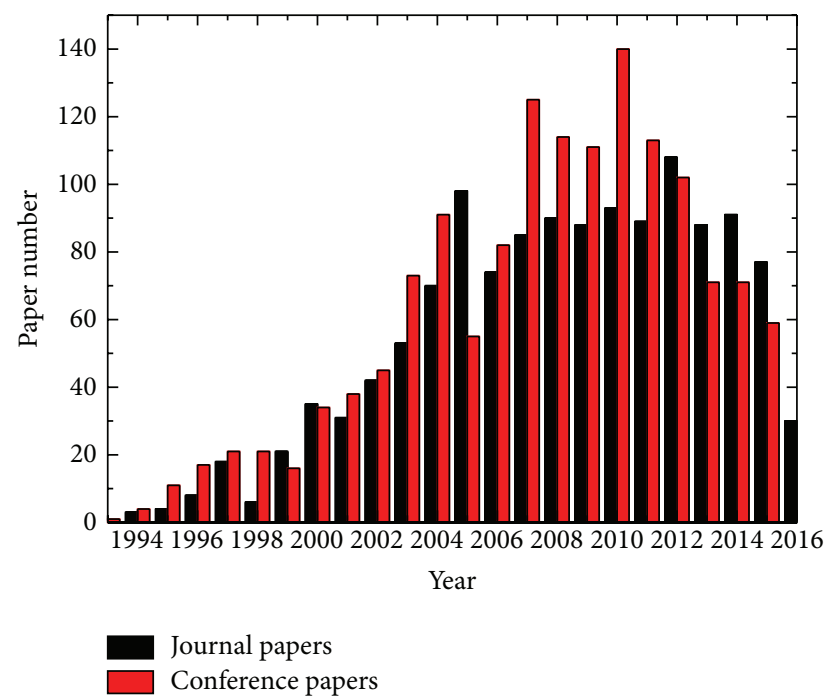

Figure 2: Papers using GAs for antenna design from 1993 to May 2016.

patch antennas with low RCS. A GA that combines chaos theory and genetic algorithm is used for designing T-shaped MIMO radar antenna array in [46]. A design procedure based on a GA is given in [47] for optimizing a patch antenna for operation to four frequency bands GSM1800, GSM1900, LTE2300, and Bluetooth.

\section{Particle Swarm Optimization (PSO)}

In PSO, the particles move in the search space, where each particle position is updated by two optimum values. The first one is the best solution (fitness) that has been achieved so far. This value is called pbest. The other one is the global best value obtained so far by any particle in the swarm. This best value is called gbest. After finding the pbest and gbest, the velocity update rule is an important factor in a PSO algorithm. The most commonly used algorithm defines that the velocity of each particle for every problem dimension is updated with the following equation:

$$
\begin{aligned}
u_{G+1, n i}= & w u_{G, n i}+c_{1} \operatorname{rand}_{1(0,1)}\left(\text { pbest }_{G+1, n i}-x_{G, n i}\right) \\
& +c_{2} \operatorname{rand}_{2(0,1)}\left(\text { gbest }_{G+1, n i}-x_{G, n i}\right),
\end{aligned}
$$

where $u_{G+1, n i}$ is the $i$ th particle velocity in the $n$th dimension, $G+1$ denotes the current iteration and $G$ denotes the previous, $x_{G, n i}$ is the particle position in the $n$th dimension, $\operatorname{rand}_{1(0,1)}$, rand $_{2(0,1)}$ are uniformly distributed random numbers in $(0,1), w$ is a parameter known as the inertia weight, and $c_{1}$ and $c_{2}$ are the learning factors.

The parameter $w$ (inertia weight) is a constant between 0 and 1 . This parameter represents the particle's fly without any external influence. The higher the value of $w$ is or the closer it is to unity, the more the particle stays unaffected from pbest and gbest. The inertia weight controls the impact of the previous velocity: a large inertia weight favors exploration, while a small inertia weight favors exploitation. The parameter $c_{1}$ represents the influence of the particle memory on its best position, while the parameter $c_{2}$ represents the influence of the swarm best position. Therefore, in the Inertia Weight PSO (IWPSO) algorithm the parameters to be determined are the swarm size (or population size), usually 100 or less, the cognitive learning factor $c_{1}$ and the social learning factor $c_{2}$ (usually both are set equal to 2.0), the inertia weight $w$, and the maximum number of iterations. It is common practice to linearly decrease the inertia weight starting from 0.9 or 0.95 to 0.4 .

Clerc [8] has suggested the use of a different velocity update rule, which has introduced a parameter $K$ called constriction factor. The role of the constriction factor is to 
TABLE 2: Selected journal papers that use PSO for antenna design.

\begin{tabular}{lll}
\hline Problem & Algorithm(s) used & Ref. \\
\hline Linear arrays design & Original PSO and CLPSO & [50,51, 63] \\
Profiled corrugated horn antenna design & Original PSO and GA and hybrid GA-PSO & O54] \\
Phased arrays design & Original PSO and GA comparison & Original PSO and DE and GA comparison \\
Circular array design & Original PSO with MoM \\
Coplanar waveguide-fed planar monopole antenna & Original PSO \\
Conformal phased arrays design & Original PSO \\
Reconfigurable phase-differentiated array design & Parallel PSO/FDTD \\
Multiband and wideband patch antenna design & Original PSO \\
Time-modulated arrays design & QPSO & [56] \\
Infinitesimal dipoles array synthesis & CLPSO \\
Yagi-Uda antenna & Modified PSO \\
Thinned planar circular arrays & Adaptive Mutated Boolean PSO \\
Adaptive beamforming of linear antenna arrays & Boolean PSO \\
Dual-band patch antenna design & Chaotic PSO \\
Array design & Hybrid PSO and Hadamard difference sets \\
Square thinned arrays & Feedback Particle Swarm Optimization (FPSO) with nonlinear \\
Linear array design & inertia weight \\
\hline
\end{tabular}

ensure convergence when all the particles have stopped their movements. The velocity update rule is then given by

$$
\begin{aligned}
& u_{G+1, n i}=K\left[u_{G, n i}+c_{1} \operatorname{rand}_{1(0,1)}\left(\text { pbest }_{G+1, n i}-x_{G, n i}\right)\right. \\
& \left.\quad+c_{2} \operatorname{rand}_{2(0,1)}\left(\text { gbest }_{G+1, n i}-x_{G, n i}\right)\right] \\
& K=\frac{2}{\left|2-\varphi-\sqrt{\varphi^{2}-4 \varphi}\right|},
\end{aligned}
$$

where $\varphi=c_{1}+c_{2}$ and $\varphi>4$. This PSO algorithm variant is known as Constriction Factor PSO (CFPSO).

The Scopus database shows a total number of 39673 papers from 1995 to April 2016 for PSO related papers (including 19570 journal papers and 18355 conference papers). A refined search for antenna papers reveals 519 journal papers and 515 conference papers from 2002 to May 2016 indicating the popularity of PSO algorithm. Figure 3 shows the distribution of papers on PSO design of antennas from 2002 to 2016.

Table 2 lists selected PSO antenna papers. Introductory and tutorial papers that introduce the application of the PSO for antenna design are $[48,49]$. Additionally, the problem of sidelobe suppression of linear arrays using the PSO has been addressed in [50,51]. A comparison of the performance of the PSO and GA algorithms, as applied to the problem of phased arrays design, has been given in [52], while a comparative study of PSO, GAs, and DE for circular array design has been reported in [53]. A performance comparison of PSO, GA, and a hybrid GA-PSO has been provided in [54], where they have been applied to the problem of designing profiled corrugated horn antennas. The application of PSO to conformal phased arrays design has been shown in [55]. A coplanar waveguidefed planar monopole antenna for multiband operation has

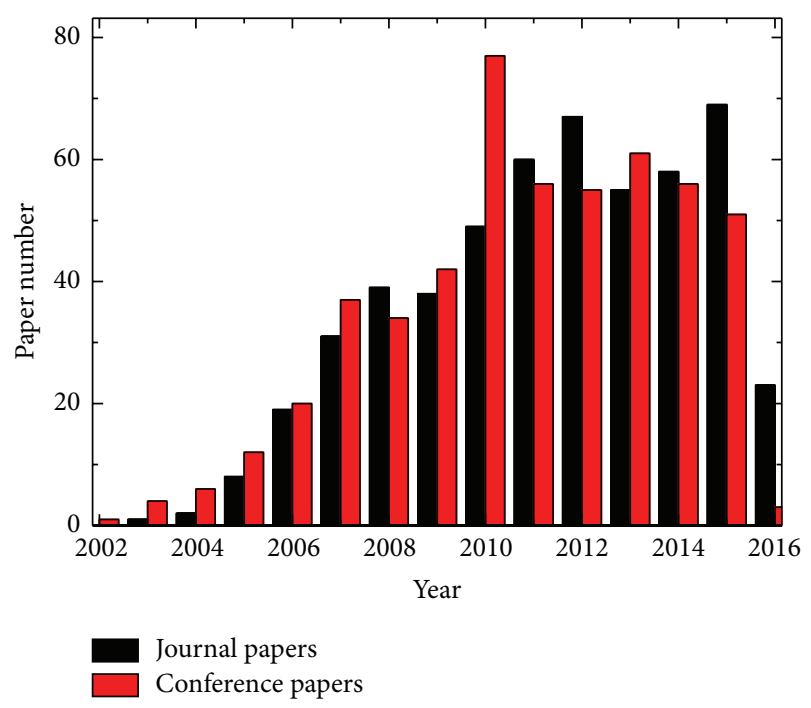

FIgUre 3: Papers using PSO for antenna design from 2002 to May 2016.

been designed in [56] using the PSO algorithm in conjunction with the Method of Moments (MoM). The authors in [57] use PSO for reconfigurable phase-differentiated array design. A Parallelized PSO optimizer has been used in conjunction with the Finite Difference Time Domain (FDTD) which has been employed for multiband patch antenna designs in [58], and the problem of minimizing power loss in timemodulated arrays has been addressed in [59]. Boundary conditions play an important role in the application of the PSO, and the performances of different boundary conditions have been tested on a 16-element array antenna in [60], based 
on mathematical benchmark functions. All of the above papers use the original IWPSO or the CFPSO, although several variants of PSO are available. A new PSO variant called quantum PSO (QPSO) algorithm has been proposed and applied in [61] to find a set of infinitesimal dipoles which produces the same near and far fields as a circular dielectric resonator antenna (DRA). The interesting point about QPSO is the fact that it contains only one control parameter. The comprehensive learning PSO (CLPSO) is applied to Yagi-Uda antenna design in [62] and unequally spaced arrays sidelobe suppression in [63]. A modified PSO algorithm has been applied in [64] for the synthesis of thinned planar circular arrays. A Feedback Particle Swarm Optimization (FPSO) is in [65] proposed for SLL minimization and null control of linear arrays. The FPSO is based on a nonlinear inertia weight algorithm.

\section{Differential Evolution (DE)}

In $\mathrm{DE}$, the initial population evolves in each generation with the use of three operators: mutation, crossover, and selection. Several DE variants or strategies exist in the literature $[13,66]$ that depend on the form of these operators. The choice of the best DE strategy depends on the problem type [67]. Common $\mathrm{DE}$ strategies for the generation of trial vectors include $\mathrm{DE} / \mathrm{rand} / 1 /$ bin, $\mathrm{DE} /$ rand-to-best/2/bin, and $\mathrm{DE} / \mathrm{rand} / 2 /$ bin. In these strategies a mutant vector $\bar{v}_{G+1, i}$ for each target vector $\bar{x}_{G, i}$ is computed by

$\mathrm{DE} / \mathrm{rand} / 1 / \mathrm{bin}$
$\bar{v}_{G+1, i}=\bar{x}_{G, r_{1}}+F\left(\bar{x}_{G, r_{2}}-\bar{x}_{G, r_{3}}\right), \quad r_{1} \neq r_{2} \neq r_{3}$

$\mathrm{DE} /$ rand-to-best/2/bin

$$
\begin{gathered}
\bar{v}_{G+1, i}=\bar{x}_{G, i}+F\left(\bar{x}_{G, \text { best }}-\bar{x}_{G, i}\right)+F\left(\bar{x}_{G, r_{1}}-\bar{x}_{G, r_{2}}\right) \\
+F\left(\bar{x}_{G, r_{3}}-\bar{x}_{G, r_{4}}\right), \quad r_{1} \neq r_{2} \neq r_{3} \neq r_{4}
\end{gathered}
$$

$\mathrm{DE} / \mathrm{rand} / 2 /$ bin

$$
\begin{aligned}
\bar{v}_{G+1, i}=\bar{x}_{G, r_{1}}+F\left(\bar{x}_{G, r_{2}}-\bar{x}_{G, r_{3}}\right)+F\left(\bar{x}_{G, r_{4}}-\bar{x}_{G, r_{5}}\right), \\
r_{1} \neq r_{2} \neq r_{3} \neq r_{4} \neq r_{5},
\end{aligned}
$$

where $r_{1}, r_{2}, r_{3}, r_{4}, r_{5}$ are randomly chosen indices from the population that are different from the index $i$ and $F$ is a mutation control parameter. After mutation, the crossover operator is applied to generate a trial vector $\bar{u}_{G+1, i}=\left(u_{G+1,1 i}, u_{G+1,2 i}, \ldots, u_{G+1, j i}, \ldots, u_{G+1, D i}\right)$ whose coordinates are given by

$$
u_{G+1, j i}= \begin{cases}v_{G+1, j i}, & \text { if } \operatorname{rand}_{j[0,1)} \leq \mathrm{CR} \text { or } j=\operatorname{rn}(i), \\ x_{G+1, j i}, & \text { if } \operatorname{rand}_{j[0,1)}>\mathrm{CR} \text { and } j \neq \mathrm{rn}(i),\end{cases}
$$

where $j=1,2, \ldots, D, \operatorname{rand}_{j[0,1)}$ is a number from a uniform random distribution from the interval $[0,1), \mathrm{rn}(i)$ is a randomly chosen index from $(1,2, \ldots, D)$, and CR is the crossover constant from the interval $[0,1]$. DE uses a

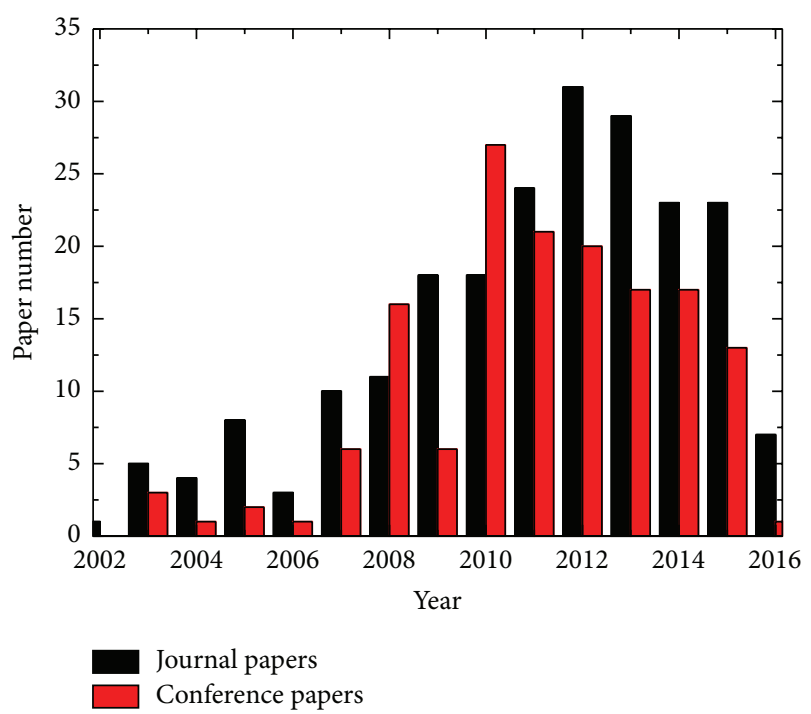

Figure 4: Papers using DE for antenna design from 2002 to May 2016.

greedy selection operator, which for minimization problems is defined by

$$
\bar{x}_{G+1, i}= \begin{cases}\bar{u}_{G+1, i}, & \text { if } f\left(\bar{u}_{G+1, i}\right)<f\left(\bar{x}_{G, i}\right), \\ \bar{x}_{G, i}, & \text { otherwise, }\end{cases}
$$

where $f\left(\bar{u}_{G+1, i}\right)$ and $f\left(\bar{x}_{G, i}\right)$ are the fitness values of the trial and the old vector, respectively. The new trial vector $\bar{u}_{G+1, i}$ replaces the old vector $\bar{x}_{G, i}$ only when it produces a lower objective-function value than the old one. Otherwise, the old vector remains in the next generation. The stopping criterion for the DE is usually the generation number or the number of objective-function evaluations.

A search in the Scopus database reveals 38,097 documents related to DE (27,482 journal papers and 7831 conference papers). A refined search for antenna related papers using the DE shows 221 journal papers and 152 conference papers. Figure 4 shows how the papers related to DE antenna are distributed from 2002 to May 2016.

A general review paper of the use of DE in electromagnetics has been reported in [68], and a book [69] on $\mathrm{DE}$ implementation in electromagnetics has been published. Table 3 lists some representative papers for antenna design. The most commonly used DE strategy for antenna design is the $\mathrm{DE} / \mathrm{rand} / \mathrm{l} / \mathrm{bin}$ variant. The above-mentioned strategy has been applied, among others, to the problem of linear array design in [70]; synthesis of difference patterns of monopulse antennas in [71]; array pattern nulling in [72]; and conformal array design in [73]. Several other DE strategies have been applied to antenna problems. In [74], the authors have introduced a new DDE/BoR/1/bin strategy for linear array synthesis, while a modified DE strategy (MDES) has been used in [75] for the same problem. The strategy DE/best/1/bin has been applied in [76-78] for timemodulated array design. Self-adaptive DE algorithms have also been applied to antenna problems, including jDE [79] 
TABLE 3: Selected journal papers that use DE for antenna design.

\begin{tabular}{|c|c|c|}
\hline Problem & Algorithm(s) used & Ref. \\
\hline Linear arrays design & $\mathrm{DE} / \mathrm{rand} / 1 / \mathrm{bin}$ & {$[70]$} \\
\hline Linear arrays design & DDE/BoR/1/bin & {$[74]$} \\
\hline Linear arrays design and E-shaped patch antenna & jDE [79] & [80-82] \\
\hline Difference patterns of monopulse antennas & $\mathrm{DE} / \mathrm{rand} / 1 / \mathrm{bin}$ & [71] \\
\hline Array pattern nulling & $\mathrm{DE} / \mathrm{rand} / 1 / \mathrm{bin}$ & {$[72]$} \\
\hline Linear arrays design & Modified DE strategy (MDES) & [75] \\
\hline Linear arrays design & Multiobjective DE & {$[87]$} \\
\hline Array design & Improved DE & [143] \\
\hline Shaped beam synthesis & CODE-EIG & {$[86]$} \\
\hline Conformal arrays design & $\mathrm{DE} / \mathrm{rand} / 1 / \mathrm{bin}$ & {$[73]$} \\
\hline Horn antenna design and sparse linear arrays synthesis & $\mathrm{SaDE}[83]$ & {$[84,85]$} \\
\hline Subarray design & Memetic GDE3 & {$[88]$} \\
\hline Time-modulated arrays design & DE/best/1/bin & [76-78] \\
\hline Monopulse antenna with a subarray weighting & Hybrid DE & {$[144]$} \\
\hline Yagi-Uda antenna & GDE3 & [89] \\
\hline Low Radar Cross Section (RCS) slot patch antenna design & $\mathrm{DE} / \mathrm{MoM}$ & [90] \\
\hline
\end{tabular}

in [80-82]; SaDE [83] in [84, 85]; and CODE-EIG in [86]. Multiobjective DE algorithms are also another large group of DE algorithms applied to antenna problems. These include applications to linear array design in [87], to subarray design in [88], and to Yagi-Uda antennas [89]. DE algorithms hybridized with other methods are also commonly found in the literature; for instance, the DE has been used with the Method of Moments in [90] for the design of low Radar Cross Section (RCS) antennas.

\section{Other Innovative Algorithms}

Several new EAs have emerged during the last ten years that are based on different evolutionary models of animals, insects, or other biological entities. Artificial Bee Colony (ABC) [7] is a recently proposed SI algorithm, which has been applied to several real-world engineering problems. The ABC algorithm models and simulates the honey bee behavior in food foraging. In the ABC algorithm, a potential solution to the optimization problem is represented by the position of a food source while the food source corresponds to the quality (objective-function fitness) of the associated solution. The ABC algorithm has been successfully applied to several problems in wireless communications [91]. A number of different variants of the $\mathrm{ABC}$ that improve the original algorithm have been proposed in [92]. A search in the Scopus database shows that there are more than 3000 papers on $A B C$, of which 48 use the ABC for antenna design. These include array design [93-96]; resonant frequency of patch antennas calculation [97]; and RFID tags design [98-100].

Ant Colony Optimization (ACO) $[6,10,11]$ is a population-based metaheuristic which was introduced by Dorigo et al. [11] inspired by the behavior of real ants. The algorithm is based on the fact that ant colonies can find the shortest path between their nest and a food source just by depositing and reacting to pheromones while they are exploring their environment. ACO is suitable for solving combinatorial optimization problems that are common in antennas. The search in Scopus shows more than 10,000 papers on ACO, with 169 papers dealing with the topic of antenna design. The topic of linear array synthesis has been presented in [101]; patch antenna design in [102]; sum-difference pattern synthesis in [103]; and thinned array design in [102]. A modified touring ant colony optimizer has been used for shaped beam synthesis [104] and for pattern nulling in [105-107]. The authors in [108] present a comparative study of simulated annealing (SA), GA, and ACO on self-structured antenna design.

Biogeography-based optimization (BBO) [109] is another later addition to EAs. BBO is based on mathematical models that describe how species migrate from one island to another, how new species arise, and how species become extinct. The way the problem solution is found is analogous to nature's way of distributing species. The search in the Scopus database yielded 654 papers that refer to BBO from 2007 to May 2016 with 40 papers that use BBO for antenna design from 2009 till today. BBO has been applied to Yagi-Uda design [110] and array synthesis [111-117]. Additionally a hybrid DE/BBO algorithm has been used for the design of a reconfigurable antenna array with discrete phase shifters in [118].

Evolutionary Programming (EP) was originally proposed by Fogel in [3]. EP is based on the idea of representing individuals phenotypically as finite state machines capable of responding to environmental stimuli. The representations used in EP are problem-dependent. The most common representation used is a fixed-length real-valued vector. In $\mathrm{EP}$, the vectors evolve but do not exchange information between them. There are no crossover operators but only mutation operators. EP has been applied to several problems in electromagnetics $[21,119,120]$. Among others EP has been applied to patch antenna design [121] and to wideband parasitic dipole arrays [122]. 
Hansen and Ostermeier [123] introduced the Covariance Matrix Adaptation Evolution Strategy (CMA-ES). CMA-ES is a second-order approach estimating a positive covariance matrix within an iterative procedure. More details about the CMA-ES performance algorithm can be found in [124, 125]. In $[23,24]$ the authors present an approach for mixedparameter optimization based on CMA-ES, which is successfully applied in several design problems in electromagnetics. This approach is based on the concepts presented in [22] for EP. The CMA-ES algorithm has been recently applied to design problems in antennas and electromagnetics in general [126-129].

5.1. Other Artificial Intelligence Methods. Other artificial intelligence methods and techniques include Artificial Neural Network (ANN) architectures [130], which are a family of models inspired by biological neural networks. ANNs are used to estimate or approximate functions that can depend on a large number of inputs and are generally unknown. The applications of ANNs to electromagnetics are a popular topic in the literature [131].

Deep learning is a type of machine learning based on a set of algorithms that attempt to model high-level abstractions in data by using a deep graph with multiple processing layers, composed of multiple linear and nonlinear transformations [132-135]. These methods have dramatically improved the state of the art in speech recognition, visual object recognition, object detection, and many other domains such as drug discovery and genomics [132].

\section{Discussion: Open Issues}

The choice of the best algorithm for every problem requires the consideration of its specific characteristics. Once the algorithm is chosen, the key issue becomes the selection of the algorithm control parameters, which in most cases can be also problem-dependent. A practical initial approach is to use the control parameters for these algorithms that commonly perform well regardless of the characteristics of the problem to be solved.

For real-coded GAs typical values are 0.9 for the crossover probability and $1 / N$ for the mutation probability, where $N$ is the problem dimension. For the binary-coded GA, typical values for crossover and mutation probabilities are [1.0, 0.8] and $[0.01,0.1]$, respectively.

In the PSO algorithms $c_{1}$ and $c_{2}$ are set equal to 2.05. For CFPSO, these values result in $K=0.7298$. For IWPSO, it is common practice to linearly decrease the inertia weight starting from 0.95 to 0.4 . The velocity is updated asynchronously, which means that the global best position is updated at the moment it is found.

For the DE, Storn and Price [13] have suggested choosing the differential evolution control parameters $F$ and $C R$ from the intervals $[0.5,1]$ and $[0.8,1]$, respectively, and setting $N P=10 D$. The correct selection of these control parameter values is, frequently, a problem-dependent task. Multiple algorithm runs are often required for fine-tuning the control parameters. There are several DE algorithms in the literature that self-adapt these control parameters. Another question is the selection of the appropriate strategy for the generation of trial vectors, which requires additional computational time using a trial-and-error search procedure. Therefore, it is not always an easy task to fine-tune the control parameters and strategy. Since finding the suitable control parameter values and strategy in such a way is often very time-consuming, there has been an increasing trend among researchers in designing new adaptive and self-adaptive DE variants. A DE strategy (jDE) that self-adapts the control parameters has been introduced in [79]. This algorithm has been applied successfully to a microwave absorber design problem [136] and linear array synthesis [82]. SaDE, a DE algorithm that self-adapts both control parameters and strategy based on learning experiences from previous generations, is presented in [83].

The research domain of evolutionary algorithms is growing rapidly. A current and growing research trend in evolutionary algorithms is their hybridization with local optimizers. These algorithms are called Memetic Algorithms (MAs) [90] that are inspired by Dawkins' notion of meme. The advantage of such an approach is that the use of a local search optimizer ensures that specific regions of the search space can be explored using fewer evaluations and good quality solutions can be generated early during the search. Furthermore, the global search algorithm generates good initial solutions for the local search. MAs can be highly efficient due to this combination of global exploration and local exploitation.

An interesting idea has been presented in [137] where the authors conceptually present the equivalences of various popular EAs like GAs, PSO, DE, and BBO. Their basic conclusion is that the conceptual equivalence of the algorithms is supported by the fact that modifications in algorithms result in very different performance levels.

Finally, another concern that is pertinent to all of the above algorithms is the definition of the stopping criterion. Usually, this is the iteration number or the number of objective-function evaluations. Additionally and in order to avoid stagnation, another criterion could be set for the algorithm to stop after a number of generations when the objective function does not further improve.

\section{Conclusion}

A brief survey of different evolutionary algorithms and their application to different problems in antennas and propagation have been presented in this review paper. It is to be noted that, among the evolutionary algorithms used in the literature, the GA and SI algorithms are among those most commonly utilized.

The bibliography statistics show that GAs, PSO, and DE are among the most popular algorithms for antenna design. It must be pointed out that several variants of these algorithms have also been employed along with other nature-inspired algorithms that have emerged. Most notably, ABC, ACO, BBO, EP, and CMA_ES have been applied to several antenna design problems. The body of literature on EAs to antenna 
design is by now quite extensive and it continues to grow fast with more innovative algorithms. The above presented algorithms have been proven effective in solving specific antenna design problems, although the NFL theorem assures that a best global optimizer does not exist. the search for new algorithms and their application to antenna design problems is an ongoing research process, which is likely to continue unabated for some time to come.

\section{Competing Interests}

The authors declare that they have no competing interests.

\section{Acknowledgments}

The work of Christos Kalialakis was supported by the EU Horizon 2020 Research and Innovation Programme under the Marie Sklodowska-Curie Grant Agreement no. 654734.

\section{References}

[1] D. E. Goldberg, Genetic Algorithms in Search, Optimization and Machine Learning, Addison-Wesley, New York, NY, USA, 1989.

[2] J. H. Holland, Adaptation in Natural and Artificial Systems, The University of Michigan Press, Ann Arbor, Mich, USA, 1975.

[3] D. B. Fogel, Evolutionary Computation: Toward a New Philosophy of Machine Intelligence, IEEE Press, Piscataway, NJ, USA, 1995.

[4] H.-G. Beyer and H.-P. Schwefel, "Evolution strategies-a comprehensive introduction," Natural Computing, vol. 1, no. 1, pp. 3-52, 2002.

[5] J. Kennedy and R. Eberhart, "Particle swarm optimization," in Proceedings of the IEEE International Conference on Neural Networks, pp. 1942-1948, Piscataway, NJ, USA, 1995.

[6] M. Dorigo and T. Stutzle, Ant Colony Optimization, The MIT Press, Cambridge, Mass, USA, 2004.

[7] D. Karaboga and B. Basturk, "A powerful and efficient algorithm for numerical function optimization: artificial bee colony (ABC) algorithm," Journal of Global Optimization, vol. 39, no. 3, pp. 459-471, 2007.

[8] M. Clerc, "The swarm and the queen: towards a deterministic and adaptive particle swarm optimization," in Proceedings of the Congress on Evolutionary Computation (CEC '99), pp. 1951-1957, IEEE, Washington, DC, USA, July 1999.

[9] J. Kennedy and R. C. Eberhart, "Discrete binary version of the particle swarm algorithm," in Proceedings of the IEEE International Conference on Systems, Man, and Cybernetics, pp. 4104-4108, Orlando, Fla, USA, October 1997.

[10] M. Dorigo and L. M. Gambardella, "Ant colonies for the travelling salesman problem," BioSystems, vol. 43, no. 2, pp. 7381, 1997.

[11] M. Dorigo, V. Maniezzo, and A. Colorni, "Ant system: optimization by a colony of cooperating agents," IEEE Transactions on Systems, Man, and Cybernetics Part B: Cybernetics, vol. 26, no. 1, pp. 29-41, 1996.

[12] R. Storn and K. Price, "Differential Evolution-A Simple and efficient adaptive scheme for global optimization over continuous spaces," 1995, http://citeseer.ist.psu.edu/article/storn95differential.html.
[13] R. Storn and K. Price, "Differential evolution-a simple and efficient heuristic for global optimization over continuous spaces," Journal of Global Optimization, vol. 11, no. 4, pp. 341359, 1997.

[14] S. Das, A. Abraham, and A. Konar, "Particle swarm optimization and differential evolution algorithms: technical analysis, applications and hybridization perspectives," in Advances of Computational Intelligence in Industrial Systems, Y. L. Liu, A. S. Sun, E. P. L. Lim, H. T. L. Loh, and W. F. L. Lu, Eds., vol. 116, pp. 1-38, Springer, Berlin, Germany, 2008.

[15] Z. Bayraktar, M. Komurcu, J. A. Bossard, and D. H. Werner, "The wind driven optimization technique and its application in electromagnetics," IEEE Transactions on Antennas and Propagation, vol. 61, no. 5, pp. 2745-2757, 2013.

[16] Z. D. Zaharis, C. Skeberis, T. D. Xenos, P. I. Lazaridis, and J. Cosmas, "Design of a novel antenna array beamformer using neural networks trained by modified adaptive dispersion invasive weed optimization based data," IEEE Transactions on Broadcasting, vol. 59, no. 3, pp. 455-460, 2013.

[17] Z. D. Zaharis, P. I. Lazaridis, J. Cosmas, C. Skeberis, and T. D. Xenos, "Synthesis of a near-optimal high-gain antenna array with main lobe tilting and null filling using taguchi initialized invasive weed optimization," IEEE Transactions on Broadcasting, vol. 60, no. 1, pp. 120-127, 2014.

[18] Y.-Y. Bai, S. Xiao, C. Liu, and B.-Z. Wang, "A hybrid IWO/PSO algorithm for pattern synthesis of conformal phased arrays," IEEE Transactions on Antennas and Propagation, vol. 61, no. 4, pp. 2328-2332, 2013.

[19] G. G. Roy, S. Das, P. Chakraborty, and P. N. Suganthan, "Design of non-uniform circular antenna arrays using a modified invasive weed optimization algorithm," IEEE Transactions on Antennas and Propagation, vol. 59, no. 1, pp. 110-118, 2011.

[20] S. Karimkashi and A. A. Kishk, "Invasive weed optimization and its features in electromagnetics," IEEE Transactions on Antennas and Propagation, vol. 58, no. 4, pp. 1269-1278, 2010.

[21] A. Hoorfar, "Evolutionary programming in electromagnetic optimization: a review," IEEE Transactions on Antennas and Propagation, vol. 55, no. 3, pp. 523-537, 2007.

[22] A. Hoorfar, J. Zhu, and S. Nelatury, "Electromagnetic optimization using a mixed-parameter self-adaptive evolutionary algorithm," Microwave and Optical Technology Letters, vol. 39, no. 4, pp. 267-271, 2003.

[23] E. Boudaher and A. Hoorfar, "Electromagnetic design optimization using mixed-parameter and multiobjective CMA-ES," in Proceedings of the IEEE Antennas and Propagation Society International Symposium (APSURSI '13), pp. 406-407, IEEE, Orlando, Fla, USA, July 2013.

[24] E. BouDaher and A. Hoorfar, "Electromagnetic optimization using mixed-parameter and multiobjective covariance matrix adaptation evolution strategy," IEEE Transactions on Antennas and Propagation, vol. 63, no. 4, pp. 1712-1724, 2015.

[25] D. H. Wolpert and W. G. Macready, "No free lunch theorems for optimization," IEEE Transactions on Evolutionary Computation, vol. 1, no. 1, pp. 67-82, 1997.

[26] Y. C. Ho and D. L. Pepyne, "Simple explanation of the no-freelunch theorem and its implications," Journal of Optimization Theory and Applications, vol. 115, no. 3, pp. 549-570, 2002.

[27] R. L. Haupt and S. E. Haupt, Practical Genetic Algorithms, 1998.

[28] R. L. Haupt and D. H. Werner, Genetic Algorithms in Electromagnetics, Wiley-Interscience, New York, NY, USA, 2007. 
[29] R. L. Haupt, "An introduction to genetic algorithms for electromagnetics," IEEE Antennas and Propagation Magazine, vol. 37, no. 2, pp. 7-15, 1995.

[30] J. M. Johnson and Y. Rahmat-Samii, "Genetic algorithms in engineering electromagnetics," IEEE Antennas and Propagation Magazine, vol. 39, no. 4, pp. 7-21, 1997.

[31] F. J. Ares-Pena, J. A. Rodriguez-Gonzalez, E. Villanueva-Lopez, and S. R. Rengarajan, "Genetic algorithms in the design and optimization of antenna array patterns," IEEE Transactions on Antennas and Propagation, vol. 47, no. 3, pp. 506-510, 1999.

[32] D. Marcano and F. Durán, "Synthesis of antenna arrays using genetic algorithms," IEEE Antennas and Propagation Magazine, vol. 42, no. 3, pp. 12-20, 2000.

[33] K.-K. Yan and Y. Lu, "Sidelobe reduction in array-pattern synthesis using genetic algorithm," IEEE Transactions on Antennas and Propagation, vol. 45, no. 7, pp. 1117-1122, 1997.

[34] R. L. Haupt, “Thinned arrays using genetic algorithms," IEEE Transactions on Antennas and Propagation, vol. 42, no. 7, pp. 993-999, 1994.

[35] B.-K. Yeo and Y. Lu, "Array failure correction with a genetic algorithm," IEEE Transactions on Antennas and Propagation, vol. 47, no. 5, pp. 823-828, 1999.

[36] S. Yang, Y. B. Gan, A. Qing, and P. K. Tan, "Design of a uniform amplitude time modulated linear array with optimized time sequences," IEEE Transactions on Antennas and Propagation, vol. 53, no. 7, pp. 2337-2339, 2005.

[37] A. Boag, A. Boag, E. Michielssen, and R. Mittra, "Design of electrically loaded wire antennas using genetic algorithms," IEEE Transactions on Antennas and Propagation, vol. 44, no. 5, pp. 687-695, 1996.

[38] E. E. Altshuler and D. S. Linden, "Wire-antenna designs using genetic algorithms," IEEE Antennas and Propagation Magazine, vol. 39, no. 2, pp. 33-43, 1997.

[39] E. A. Jones and W. T. Joines, "Design of yagi-uda antennas using genetic algorithms," IEEE Transactions on Antennas and Propagation, vol. 45, no. 9, pp. 1386-1392, 1997.

[40] E. E. Altshuler, "Electrically small self-resonant wire antennas optimized using a genetic algorithm," IEEE Transactions on Antennas and Propagation, vol. 50, no. 3, pp. 297-300, 2002.

[41] J. Michael Johnson, "Genetic algorithms and method of moments (GA/MOM) for the design of integrated antennas," IEEE Transactions on Antennas and Propagation, vol. 47, no. 10, pp. 1606-1614, 1999.

[42] F. J. Villegas, T. Cwik, Y. Rahmat-Samii, and M. Manteghi, "A parallel electromagnetic genetic-algorithm optimization (EGO) application for patch antenna design," IEEE Transactions on Antennas and Propagation, vol. 52, no. 9, pp. 2424-2435, 2004.

[43] G. Marrocco, "Gain-optimized self-resonant meander line antennas for RFID applications," IEEE Antennas and Wireless Propagation Letters, vol. 2, pp. 302-305, 2003.

[44] R. L. Haupt, "Antenna design with a mixed integer genetic algorithm," IEEE Transactions on Antennas and Propagation, vol. 55, no. 3, pp. 577-582, 2007.

[45] X. Zhu, W. Shao, J.-L. Li, and Y. Dong, "Design and optimization of low RCS patch antennas based on a genetic algorithm," Progress in Electromagnetics Research, vol. 122, pp. 327-339, 2012.

[46] X. Fu, X. Chen, Q. Hou, Z. Wang, and Y. Yin, "An improved chaos genetic algorithm for T-shaped MIMO radar antenna array optimization," International Journal of Antennas and Propagation, vol. 2014, Article ID 631820, 6 pages, 2014.
[47] J. M. J. W. Jayasinghe, J. Anguera, D. N. Uduwawala, and A. Andújar, "Nonuniform overlapping method in designing microstrip patch antennas using genetic algorithm optimization," International Journal of Antennas and Propagation, vol. 2015, Article ID 805820, 8 pages, 2015.

[48] N. Jin and Y. Rahmat-Samii, "Advances in particle swarm optimization for antenna designs: real-number, binary, singleobjective and multiobjective implementations," IEEE Transactions on Antennas and Propagation, vol. 55, no. 3, pp. 556-567, 2007.

[49] J. Robinson and Y. Rahmat-Samii, "Particle swarm optimization in electromagnetics," IEEE Transactions on Antennas and Propagation, vol. 52, no. 2, pp. 397-407, 2004.

[50] M. M. Khodier and C. G. Christodoulou, "Linear array geometry synthesis with minimum sidelobe level and null control using particle swarm optimization," IEEE Transactions on Antennas and Propagation, vol. 53, no. 8, pp. 2674-2679, 2005.

[51] P. J. Bevelacqua and C. A. Balanis, "Minimum sidelobe levels for linear arrays," IEEE Transactions on Antennas and Propagation, vol. 55, no. 12, pp. 3442-3449, 2007.

[52] D. W. Boeringer and D. H. Werner, "Particle swarm optimization versus genetic algorithms for phased array synthesis," IEEE Transactions on Antennas and Propagation, vol. 52, no. 3, pp. 771-779, 2004.

[53] M. A. Panduro, C. A. Brizuela, L. I. Balderas, and D. A. Acosta, "A comparison of genetic algorithms, particle swarm optimization and the differential evolution method for the design of scannable circular antenna arrays," Progress in Electromagnetics Research B, vol. 13, pp. 171-186, 2009.

[54] J. Robinson, S. Sinton, and Y. Rahmat-Samii, "Particle swarm, genetic algorithm, and their hybrids: optimization of a profiled corrugated horn antenna," in Proceedings of the IEEE Antennas and Propagation Society International Symposium, pp. 314-317, San Antonio, Tex, USA, June 2002.

[55] D. W. Boeringer and D. H. Werner, "Efficiency-constrained particle swarm optimization of a modified Bernstein polynomial for conformal array excitation amplitude synthesis," IEEE Transactions on Antennas and Propagation, vol. 53, no. 8, pp. 2662-2673, 2005.

[56] W.-C. Liu, "Design of a multiband CPW-fed Monopole antenna using a particle swarm optimization approach," IEEE Transactions on Antennas and Propagation, vol. 53, no. 10, pp. 32733279, 2005.

[57] D. Gies and Y. Rahmat-Samii, "Particle swarm optimization for reconfigurable phase-differentiated array design," Microwave and Optical Technology Letters, vol. 38, no. 3, pp. 168-175, 2003.

[58] N. Jin and Y. Rahmat-Samii, "Parallel particle swarm optimization and finite-difference time-domain (PSO/FDTD) algorithm for multiband and wide-band patch antenna designs," IEEE Transactions on Antennas and Propagation, vol. 53, no. 11, pp. 3459-3468, 2005.

[59] L. Poli, P. Rocca, L. Manica, and A. Massa, "Handling sideband radiations in time-modulated arrays through particle swarm optimization," IEEE Transactions on Antennas and Propagation, vol. 58, no. 4, pp. 1408-1411, 2010.

[60] S. Xu and Y. Rahmat-Samii, "Boundary conditions in particle swarm optimization revisited," IEEE Transactions on Antennas and Propagation, vol. 55, no. 3, pp. 760-765, 2007.

[61] S. M. Mikki and A. A. Kishk, "Quantum particle swarm optimization for electromagnetics," IEEE Transactions on Antennas and Propagation, vol. 54, no. 10, pp. 2764-2775, 2006. 
[62] S. Baskar, A. Alphones, P. M. Suganthan, and J. J. Liang, "Design of Yagi-Uda antennas using comprehensive learning particle swarm optimisation," IEE Proceedings-Microwaves, Antennas and Propagation, vol. 152, no. 5, pp. 340-346, 2005.

[63] S. K. Goudos, V. Moysiadou, T. Samaras, K. Siakavara, and J. N. Sahalos, "Application of a comprehensive learning particle swarm optimizer to unequally spaced linear array synthesis with sidelobe level suppression and null control," IEEE Antennas and Wireless Propagation Letters, vol. 9, pp. 125-129, 2010.

[64] N. Pathak, G. K. Mahanti, S. K. Singh, J. K. Mishra, and A. Chakraborty, "Synthesis of thinned planar circular array antennas using modified particle swarm optimization," Progress in Electromagnetics Research Letters, vol. 12, pp. 87-97, 2009.

[65] C. Han and L. Wang, "Array pattern synthesis using particle swarm optimization with dynamic inertia weight," International Journal of Antennas and Propagation, vol. 2016, Article ID 1829458, 7 pages, 2016.

[66] R. Storn, "Differential evolution research-trends and open questions," Studies in Computational Intelligence, vol. 143, pp. 131, 2008.

[67] E. Mezura-Montes, J. Velázquez-Reyes, and C. A. Coello Coello, "A comparative study of differential evolution variants for global optimization," in Proceedings of the 8th Annual Genetic and Evolutionary Computation Conference (GECCO '06), pp. 485492, Seattle, Wash, USA, July 2006.

[68] P. Rocca, G. Oliveri, and A. Massa, "Differential evolution as applied to electromagnetics," IEEE Antennas and Propagation Magazine, vol. 53, no. 1, pp. 38-49, 2011.

[69] A. Qing, Differential Evolution: Fundamentals and Applications in Electrical Engineering, John Wiley \& Sons, New York, NY, USA, 2009.

[70] D. G. Kurup, M. Himdi, and A. Rydberg, "Synthesis of uniform amplitude unequally spaced antenna arrays using the differential evolution algorithm," IEEE Transactions on Antennas and Propagation, vol. 51, no. 9, pp. 2210-2217, 2003.

[71] S. Caorsi, A. Massa, M. Pastorino, and A. Randazzo, "Optimization of the difference patterns for monopulse antennas by a hybrid real/integer-coded differential evolution method," IEEE Transactions on Antennas and Propagation, vol. 53, no. 1, pp. 372-376, 2005.

[72] S. Yang, Y. B. Gan, and A. Qing, "Antenna-array pattern nulling using a differential evolution algorithm," International Journal of RF and Microwave Computer-Aided Engineering, vol. 14, no. 1, pp. 57-63, 2004.

[73] J.-L. Guo and J.-Y. Li, "Pattern synthesis of conformal array antenna in the presence of platform using differential evolution algorithm," IEEE Transactions on Antennas and Propagation, vol. 57, no. 9, pp. 2615-2621, 2009.

[74] C. Lin, A. Qing, and Q. Feng, "Synthesis of unequally spaced antenna arrays by using differential evolution," IEEE Transactions on Antennas and Propagation, vol. 58, no. 8, pp. 2553-2561, 2010.

[75] Y. Chen, S. Yang, and Z. Nie, “The application of a modified differential evolution strategy to some array pattern synthesis problems," IEEE Transactions on Antennas and Propagation, vol. 56, no. 7, pp. 1919-1927, 2008.

[76] S. Yang, Y. B. Gan, and A. Qing, "Sideband suppression in timemodulated linear arrays by the differential evolution algorithm," IEEE Antennas and Wireless Propagation Letters, vol. 1, pp. 173175, 2002.
[77] G. Li, S. Yang, Y. Chen, and Z. Nie, "A novel electronic beam steering technique in time modulated antenna arrays," Progress in Electromagnetics Research, vol. 97, pp. 391-405, 2009.

[78] S. Yang, Y. B. Gan, and P. K. Tan, "A new technique for power-pattern synthesis in time-modulated linear arrays," IEEE Antennas and Wireless Propagation Letters, vol. 2, pp. 285-287, 2003.

[79] J. Brest, S. Greiner, B. Bošković, M. Mernik, and V. Zumer, "Self-adapting control parameters in differential evolution: a comparative study on numerical benchmark problems," IEEE Transactions on Evolutionary Computation, vol. 10, no. 6, pp. 646-657, 2006.

[80] S. K. Goudos, A. A. Nanos, T. Samaras, K. Siakavara, E. Vafiadis, and J. N. Sahalos, "Unequally spaced arrays synthesis using self-adaptive differential evolution," in Proceedings of the 5th European Conference on Antennas and Propagation (EUCAP '11), pp. 983-986, April 2011.

[81] S. K. Goudos, K. Siakavara, T. Samaras, E. E. Vafiadis, and J. N. Sahalos, "Self-adaptive differential evolution applied to real-valued antenna and microwave design problems," IEEE Transactions on Antennas and Propagation, vol. 59, no. 4, pp. 1286-1298, 2011.

[82] N. Dib, S. K. Goudos, and H. Muhsen, "Application of Taguchi's optimization method and self-adaptive differential evolution to the synthesis of linear antenna arrays," Progress in Electromagnetics Research, vol. 102, pp. 159-180, 2010.

[83] A. K. Qin, V. L. Huang, and P. N. Suganthan, "Differential evolution algorithm with strategy adaptation for global numerical optimization," IEEE Transactions on Evolutionary Computation, vol. 13, no. 2, pp. 398-417, 2009.

[84] S. K. Goudos, K. Siakavara, T. Samaras, E. E. Vafiadis, and J. N. Sahalos, "Sparse linear array synthesis with multiple constraints using differential evolution with strategy adaptation," IEEE Antennas and Wireless Propagation Letters, vol. 10, pp. 670-673, 2011.

[85] D. Pappas, S. K. Goudos, K. B. Baltzis, and K. Siakavara, "Design of optimum gain pyramidal horn using self-adaptive differential evolution algorithms," International Journal of $R F$ and Microwave Computer-Aided Engineering, vol. 21, no. 1, pp. 59-66, 2011.

[86] S. K. Goudos, "Shaped beam pattern synthesis of antenna arrays using composite differential evolution with eigenvectorbased crossover operator," International Journal of Antennas and Propagation, vol. 2015, Article ID 295012, 10 pages, 2015.

[87] S. Pal, B. Y. Qu, S. Das, and P. N. Suganthan, "Optimal synthesis of linear antenna arrays with multi-objective differential evolution," Progress in Electromagnetics Research B, vol. 21, pp. 87-111, 2010.

[88] S. K. Goudos, K. A. Gotsis, K. Siakavara, E. E. Vafiadis, and J. N. Sahalos, "A multi-objective approach to subarrayed linear antenna arrays design based on memetic differential evolution," IEEE Transactions on Antennas and Propagation, vol. 61, no. 6, pp. 3042-3052, 2013.

[89] S. K. Goudos, K. Siakavara, E. E. Vafiadis, and J. N. Sahalos, "Pareto optimal yagi-uda antenna design using multi-objective differential evolution," Progress in Electromagnetics Research, vol. 105, pp. 231-251, 2010.

[90] W. Wang, S. Gong, X. Wang, Y. Guan, and W. Jiang, "Differential evolution algorithm and method of moments for the design of low-RCS antenna," IEEE Antennas and Wireless Propagation Letters, vol. 9, pp. 295-298, 2010. 
[91] Y. Wang, W. Chen, and C. Tellambura, "A PAPR reduction method based on artificial bee colony algorithm for OFDM signals," IEEE Transactions on Wireless Communications, vol. 9, no. 10, pp. 2994-2999, 2010.

[92] G. Zhu and S. Kwong, "Gbest-guided artificial bee colony algorithm for numerical function optimization," Applied Mathematics and Computation, vol. 217, no. 7, pp. 3166-3173, 2010.

[93] B. Basu and G. K. Mahanti, "Fire fly and artificial bees colony algo-rithm for synthesis of scanned and broad-side linear array antenna," Progress In Electromagnetics Research B, vol. 32, pp. 169-190, 2011.

[94] X. Li and M. Yin, "Hybrid differential evolution with artificial bee colony and its application for design of a reconfigurable antenna array with discrete phase shifte," IET Microwaves, Antennas and Propagation, vol. 6, no. 14, pp. 1573-1582, 2012.

[95] J. Yang, W.-T. Li, X.-W. Shi, L. Xin, and J.-F. Yu, "A hybrid $\mathrm{ABC}-\mathrm{DE}$ algorithm and its application for time-modulated arrays pattern synthesis," IEEE Transactions on Antennas and Propagation, vol. 61, no. 11, pp. 5485-5495, 2013.

[96] M. A. Zaman, M. Gaffar, M. M. Alam, S. A. Mamun, and M. A. Matin, "Synthesis of antenna arrays using artificial bee colony optimization algorithm," International Journal of Microwave and Optical Technology, vol. 6, no. 4, pp. 234-241, 2011.

[97] A. Akdagli and A. Toktas, "A novel expression in calculating resonant frequency of $\mathrm{H}$-shaped compact microstrip antennas obtained by using artificial bee colony algorithm," Journal of Electromagnetic Waves and Applications, vol. 24, no. 14-15, pp. 2049-2061, 2010.

[98] S. K. Goudos, K. Siakavara, and J. N. Sahalos, "Novel spiral antenna design using artificial bee colony optimization for UHF RFID applications," IEEE Antennas and Wireless Propagation Letters, vol. 13, pp. 528-531, 2014.

[99] S. K. Goudos, K. Siakavara, and J. N. Sahalos, "Design of load-ended spiral antennas for RFID UHF passive tags using improved artificial bee colony algorithm," AEU-International Journal of Electronics and Communications, vol. 69, no. 1, pp. 206-214, 2015.

[100] S. K. Goudos, K. Siakavara, A. Theopoulos, E. E. Vafiadis, and J. N. Sahalos, "Application of Gbest-guided artificial bee colony algorithm to passive UHF RFID tag design," International Journal of Microwave and Wireless Technologies, vol. 8, no. 3, pp. 537-545, 2016.

[101] E. Rajo-lglesias and Ó. Quevedo-Teruel, "Linear array synthesis using an ant-colony-optimization-based algorithm," IEEE Antennas and Propagation Magazine, vol. 49, no. 2, pp. 70-79, 2007.

[102] Ó. Quevedo-Teruel and E. Rajo-Iglesias, "Ant colony optimization in thinned array synthesis with minimum sidelobe level," IEEE Antennas and Wireless Propagation Letters, vol. 5, no. 1, pp. 349-352, 2006.

[103] P. Rocca, L. Manica, and A. Massa, "An improved excitation matching method based on an ant colony optimization for suboptimal-free clustering in sum-difference compromise synthesis," IEEE Transactions on Antennas and Propagation, vol. 57, no. 8, pp. 2297-2306, 2009.

[104] A. A. Akdagli, K. Guney, and D. Karaboga, “Touring ant colony optimization algorithm for shaped-beam pattern synthesis of linear antenna," Electromagnetics, vol. 26, no. 8, pp. 615-628, 2006.

[105] A. Akdagli, K. Güney, and D. Karaboga, "Pattern nulling of linear antenna arrays by controlling only the element positions with the use of improved touring ant colony optimization algorithm," Journal of Electromagnetic Waves and Applications, vol. 16, no. 10, pp. 1423-1441, 2002.

[106] D. Karaboga, K. Guney, and A. Akdagli, "Antenna array pattern nulling by controlling both amplitude and phase using modified touring ant colony optimization algorithm," International Journal of Electronics, vol. 91, no. 4, pp. 241-251, 2004.

[107] N. Karaboga, K. Güney, and A. Akdagli, "Null steering of linear antenna arrays with use of modified touring ant colony optimization algorithm," International Journal of RF and Microwave Computer-Aided Engineering, vol. 12, no. 4, pp. 375-383, 2002.

[108] C. M. Coleman, E. J. Rothwell, and J. E. Ross, "Investigation of simulated annealing, ant-colony optimization, and genetic algorithms for self-structuring antennas," IEEE Transactions on Antennas and Propagation, vol. 52, no. 4, pp. 1007-1014, 2004.

[109] D. Simon, “Biogeography-based optimization," IEEE Transactions on Evolutionary Computation, vol. 12, no. 6, pp. 702-713, 2008.

[110] U. Singh, H. Kumar, and T. S. Kamal, "Design of Yagi-Uda antenna using biogeography based optimization," IEEE Transactions on Antennas and Propagation, vol. 58, no. 10, pp. 33753379, 2010.

[111] U. Singh, H. Kumar, and T. S. Kamal, "Linear array synthesis using biogeography based optimization," Progress in Electromagnetics Research $M$, vol. 11, pp. 25-36, 2010.

[112] A. Sharaqa and N. Dib, "Design of linear and elliptical antenna arrays using biogeography based optimization," Arabian Journal for Science and Engineering, vol. 39, no. 4, pp. 2929-2939, 2014.

[113] N. Dib and A. Sharaqa, "Design of non-uniform concentric circular antenna arrays with optimal sidelobe level reduction using biogeography-based optimization," International Journal of Microwave and Wireless Technologies, vol. 7, no. 2, pp. 161-166, 2015.

[114] A. Sharaqa and N. Dib, "Position-only side lobe reduction of a uniformly excited elliptical antenna array using evolutionary algorithms," IET Microwaves, Antennas and Propagation, vol. 7, no. 6, pp. 452-457, 2013.

[115] U. Singh and T. S. Kamal, "Design of non-uniform circular antenna arrays using biogeography-based optimisation," IET Microwaves, Antennas and Propagation, vol. 5, no. 11, pp. 13651370, 2011.

[116] U. Singh and T. S. Kamal, "Synthesis of thinned planar concentric circular antenna arrays using biogeography-based optimisation," IET Microwaves, Antennas and Propagation, vol. 6, no. 7, pp. 822-829, 2012.

[117] S. K. Goudos, K. B. Baltzis, K. Siakavara, T. Samaras, E. Vafiadis, and J. N. Sahalos, "Reducing the number of elements in linear arrays using biogeography-based optimization," in Proceedings of the 6th European Conference on Antennas and Propagation (EuCAP '12), pp. 1615-1618, Prague, Czech Republic, March 2012.

[118] X. Li and M. Yin, "Hybrid differential evolution with biogeography-based optimization for design of a reconfigurable antenna array with discrete phase shifters," International Journal of Antennas and Propagation, vol. 2011, Article ID 685629, 12 pages, 2011.

[119] A. Hoorfar, S. Lakhani, and V. Jamnejad, "Application of lévy mutation operator in evolutionary programming optimization of antennas," in Proceedings of the International Conference on Electromagnetics in Advanced Applications (ICEAA '07), pp. 191194, IEEE, Torino, Italy, September 2007. 
[120] A. Hoorfar and Y. Liu, "Antenna optimization using an evolutionary programming algorithm with a hybrid mutation operator," in Proceedings of the in IEEE Antennas and Propagation Society, AP-S International Symposium (Digest), pp. 1026-1029, Salt Lake City, UT, USA, July 2000.

[121] R. Sánchez-Montero, S. Salcedo-Sanz, J. A. Portilla-Figueras, and R. J. Langley, "Hybrid PIFA-patch antenna optimized by evolutionary programming," Progress in Electromagnetics Research, vol. 108, pp. 221-234, 2010.

[122] G. A. Casula, G. Mazzarella, and N. Sirena, "Evolutionary design of wide-band parasitic dipole arrays," IEEE Transactions on Antennas and Propagation, vol. 59, no. 11, pp. 4094-4102, 2011.

[123] N. Hansen and A. Ostermeier, "Completely derandomized selfadaptation in evolution strategies," Evolutionary Computation, vol. 9, no. 2, pp. 159-195, 2001.

[124] N. Hansen, "The CMA evolution strategy: a comparing review," Studies in Fuzziness and Soft Computing, vol. 192, pp. 75-102, 2006.

[125] N. Hansen and S. Kern, "Evaluating the CMA evolution strategy on multimodal test functions," in Parallel Problem Solving from Nature-PPSN VIII, X. Yao, E. K. Burke, J. A. Lozano et al., Eds., vol. 3242 of Lecture Notes in Computer Science, pp. 282291, Springer, 2004.

[126] M. D. Gregory, Z. Bayraktar, and D. H. Werner, "Fast optimization of electromagnetic design problems using the covariance matrix adaptation evolutionary strategy," IEEE Transactions on Antennas and Propagation, vol. 59, no. 4, pp. 1275-1285, 2011.

[127] M. D. Gregory, S. V. Martin, and D. H. Werner, "A comparison of CMA-ES with other real-coded strategies used in electromagnetics design," in Proceedings of the IEEE Antennas and Propagation Society International Symposium (APSURSI '14), pp. 1962-1963, IEEE, Memphis, Tenn, USA, July 2014.

[128] A. A. Al-Azza, F. J. Harackiewicz, and H. R. Gorla, "Covariance matrix adaptation evolutionary strategy optimization of patch antenna for wireless communication," Progress in Electromagnetics Research Letters, vol. 54, pp. 85-91, 2015.

[129] X. S. Fang, C. K. Chow, K. W. Leung, and E. H. Lim, "New single-/dual-mode design formulas of the rectangular dielectric resonator antenna using covariance matrix adaptation evolutionary strategy," IEEE Antennas and Wireless Propagation Letters, vol. 10, pp. 734-737, 2011.

[130] S. Haykin, Neural Networks: A Comprehensive Foundation, Macmillan, New York, NY, USA, 1994.

[131] C. Christodoulou and M. Georgiopoulos, Applications of Neural Networks in Electromagnetics, Artech House, Norwood, Mass, USA, 2001.

[132] Y. Lecun, Y. Bengio, and G. Hinton, “Deep learning," Nature, vol. 521, no. 7553, pp. 436-444, 2015.

[133] L. Deng and D. Yu, "Deep learning: methods and applications," Foundations and Trends ${ }^{\circledR}$ in Signal Processing, vol. 7, no. 3-4, pp. 197-391, 2014.

[134] I. Arel, D. Rose, and T. Karnowski, "Deep machine learning-a new frontier in artificial intelligence research," IEEE Computational Intelligence Magazine, vol. 5, no. 4, pp. 13-18, 2010.

[135] J. Schmidhuber, "Deep learning in neural networks: an overview," Neural Networks, vol. 61, pp. 85-117, 2015.

[136] S. K. Goudos, "Design of Microwave broadband absorbers using a self-adaptive differential evolution algorithm," International Journal of RF and Microwave Computer-Aided Engineering, vol. 19, no. 3, pp. 364-372, 2009.
[137] H. Ma, D. Simon, M. Fei, and Z. Chen, "On the equivalences and differences of evolutionary algorithms," Engineering Applications of Artificial Intelligence, vol. 26, no. 10, pp. 2397-2407, 2013.

[138] L. Cen, Z. L. Yu, W. Ser, and W. Cen, "Linear aperiodic array synthesis using an improved genetic algorithm," IEEE Transactions on Antennas and Propagation, vol. 60, no. 2, pp. 895-902, 2012.

[139] Z. D. Zaharis and T. V. Yioultsis, "A novel adaptive beamforming technique applied on linear antenna arrays using adaptive mutated Boolean PSO," Progress in Electromagnetics Research, vol. 117, pp. 165-179, 2011.

[140] F. Afshinmanesh, A. Marandi, and M. Shahabadi, "Design of a single-feed dual-band dual-polarized printed microstrip antenna using a Boolean particle swarm optimization," IEEE Transactions on Antennas and Propagation, vol. 56, no. 7, pp. 1845-1852, 2008.

[141] W.-B. Wang, Q.-Y. Feng, and D. Liu, "Application of chaotic particle swarm optimization algorithm to pattern synthesis of antenna arrays," Progress in Electromagnetics Research, vol. 115, pp. 173-189, 2011.

[142] M. Donelli, A. Martini, and A. Massa, "A hybrid approach based on PSO and hadamard difference sets for the synthesis of square thinned arrays," IEEE Transactions on Antennas and Propagation, vol. 57, no. 8, pp. 2491-2495, 2009.

[143] R. Li, L. Xu, X.-W. Shi, N. Zhang, and Z.-Q. Lv, "Improved differential evolution strategy for antenna array pattern synthesis problems," Progress in Electromagnetics Research, vol. 113, pp. 429-441, 2011.

[144] A. Massa, M. Pastorino, and A. Randazzo, "Optimization of the directivity of a monopulse antenna with a subarray weighting by a hybrid differential evolution method," IEEE Antennas and Wireless Propagation Letters, vol. 5, no. 1, pp. 155-158, 2006. 


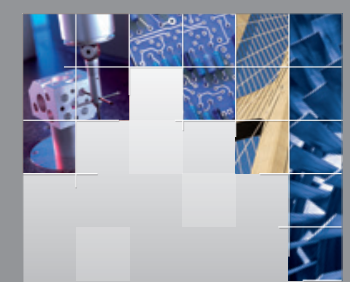

\section{Enfincering}
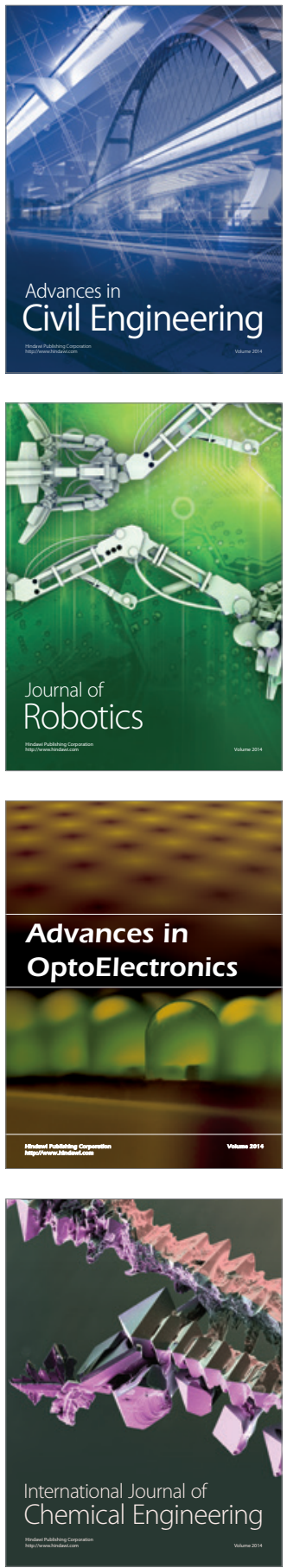

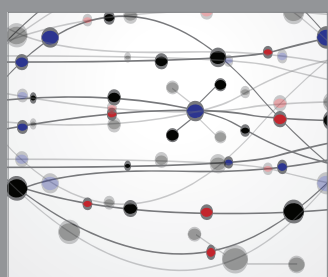

The Scientific World Journal

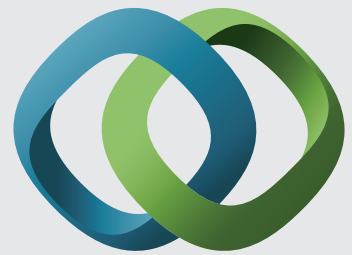

\section{Hindawi}

Submit your manuscripts at

http://www.hindawi.com
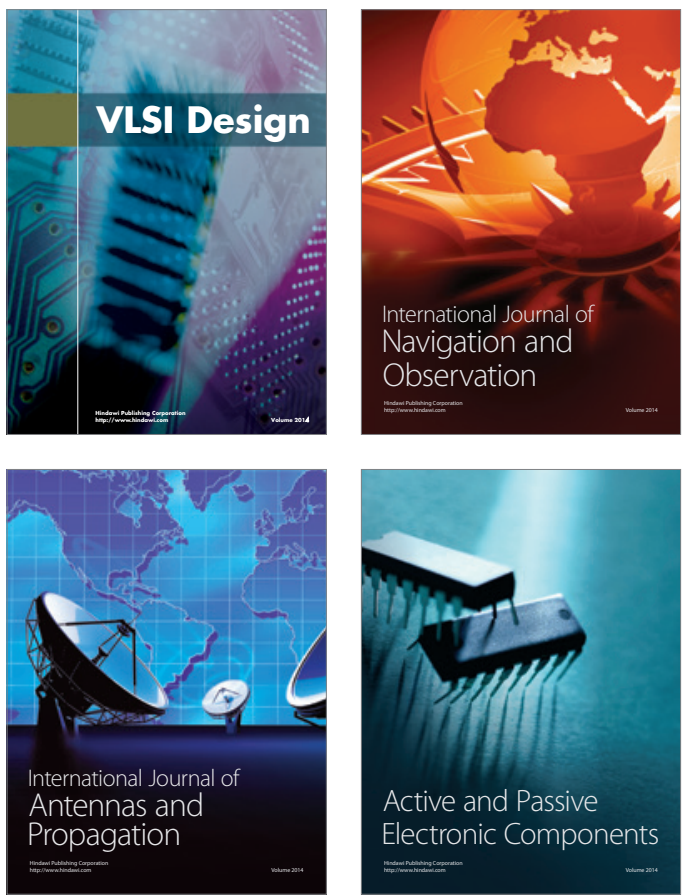
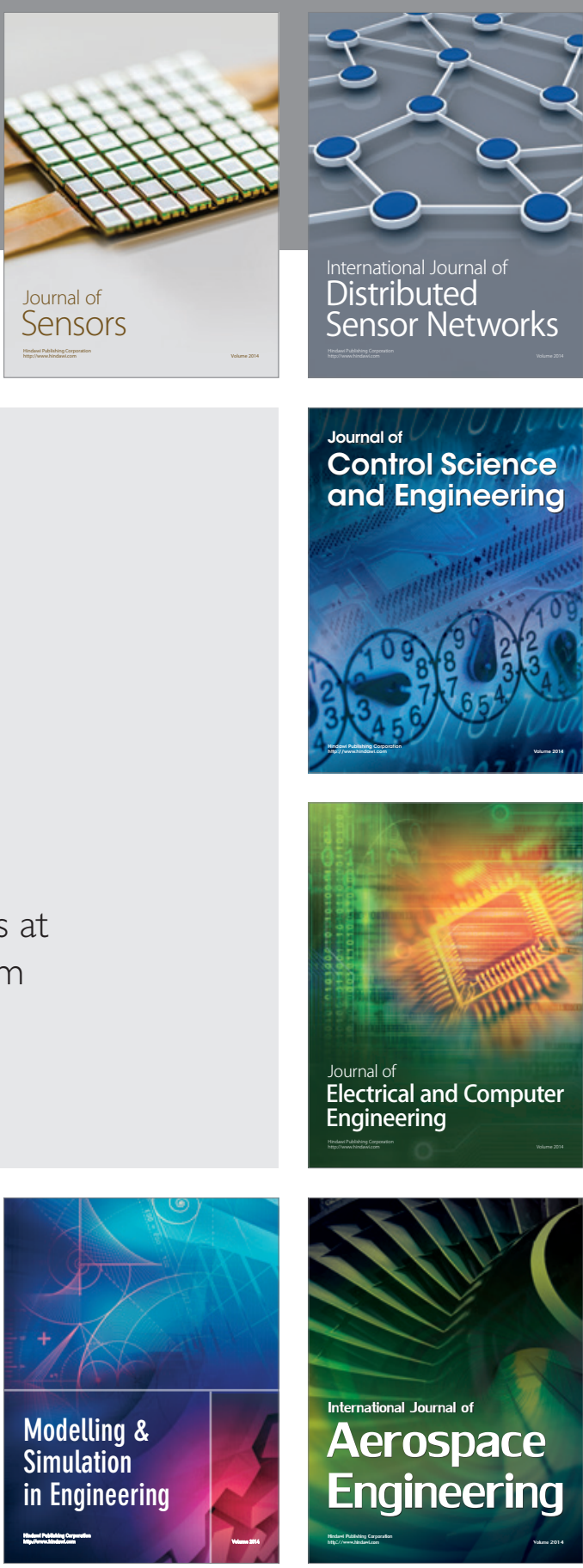

International Journal of

Distributed

Sensor Networks

Journal of

Control Science

and Engineering
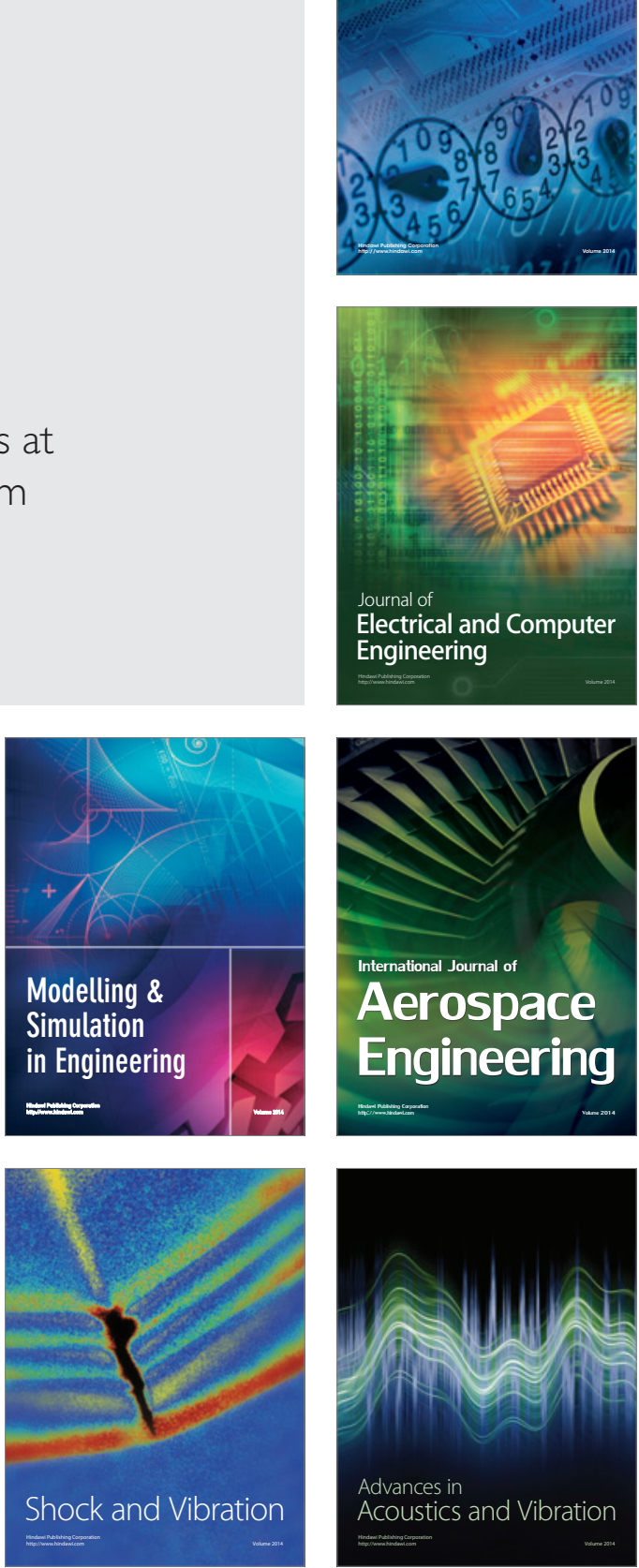